\title{
Direitos humanos e formação profissional no ensino superior
}

Ana Cristina Silva Daxenberger"

https://doi.org/10.11606/issn.1981-4690.v35i3p125-130
*Universidade

Federal da Paraíba, João Pessoa, PB, Brasil.

\section{Resumo}

Os estudos no campo de direitos humanos têm se consolidado nasúltimas décadas, principalmente, após a proclamação da Constituição Federal, de 1988, que reconhece o indivíduo como sujeito de direitos. Considerandoisso,opresenteartigotemcomoobjetivoapresentarquaissãoospressupostosteórico-práticos queestão presentena formação degraduandos dos cursos do Centro deCiências Agrárias da Universidade Federal daParaíbaem relaçãoàformaçãocidadãem direitoshumanoseapresentarcomoissosedesenvolve. Pensar em educação em direitos humanos se faz necessário na formação profissional, no ensino superior, considerando que todos os profissionais assumem responsabilidades técnicas e sociais ao exercerem sua atuação. Conhecer a realidade social é diferencial na formação profissional e pode favorecer discussõese proposições práticas para compreender a realidade e modificá-la.

Palavras-Chave: Cidadania; Formação técnica; Direitos Humanos.

\section{Introdução}

Ao ser convidada para participar do "Seminário de Direitos Humanos em Educação Física e Esporte: desafios e perspectivas", promovido pelo Núcleo de Direitos Humanos da Escola de Educação Física e Esporte (EEFE) da Universidade de São Paulo (USP), deparei-me com uma polêmica pessoal sobre o que trazer aos participantes em relação à temática a qual dedico estudo há alguns: escolher o que falar aos participantes em relação a inclusão social e, consequentemente, direitos humanos. A polêmica se dava em virtude da amplitude de minha área de estudos e a área específica a que me foi proposta debater, que é o campo dos Direitos humanos na formação profissional de universitários. Para isso, inicialmente, organizei uma discussão acerca dos aspectos vinculados à formação profissional no ensino superior, partindo de minha experiência profissional como professora, na Universidade Federal da Paraíba (UFPB), no Cento de Ciências Agrárias (CCA), no município de Areia, cerca de $120 \mathrm{~km} \mathrm{da}$ capital do estado.
Pretendo aqui trazer alguns aspectos teóricos e também práticos em termos de formação acadêmica discutindo sobre a área de Direitos Humanos, que é tão importante para a futura atuação profissional de graduandos. A isso, faz-se necessário, apresentar, inicialmente, os pressupostos teóricos que, em minha compreensão, são essências para a discussão sobre Direitos Humanos. Em seguida, explicito como ocorre a formação de graduandos dos cursos de bacharelados e licenciaturas, em nosso centro acadêmico, a partir de algumas disciplinas. Vale ressaltar que temos sete cursos, sendo eles: Agronomia, Zootecnia, Medicina Veterinária, Licenciatura e Bacharelado em Ciências Biológicas e Licenciatura e Bacharelado em Química.

Nesse artigo, o objetivo é apresentar quais são os pressupostos teórico-práticos que estão presente na formação de graduandos dos cursos do CCA/UFPB em relação à formação cidadã em Direitos Humanos e apresentar como isso se desenvolve. 
Pressupostos teóricos que sustentam a formação em Direitos Humanos nos cursos de graduação, em minha experiência

Inicialmente, entendo ser necessário apresentar o que entendo como Educação em Direitos Humanos. Como Pequeno ${ }^{1}$ afirma:

Os direitos humanos servem, para assegurar ao homem o exercício da liberdade, a preservação da dignidade e a proteção da sua existência. Trata-se, portanto, daqueles direitos considerados fundamentais, que tornam os homens iguais, independentemente do sexo, nacionalidade, etnia, classe social. Profissão, opção política, crença religiosa, convicção moral, orientação sexual e identidade de gênero. Eles são essenciais à conquista de uma vida digna, daí serem considerados fundamentais à nossa existência. (p. 24) ${ }^{1}$

Os direitos humanos estão baseados na dignidade humana, a qual define a essência do ser, do homem, ou o que podemos dizer o valor que confere a humanidade aos homens. Sendo assim, ao se pensar em formação humana, não podemos deixar de discutir e proporcionar a formação em direitos humanos, uma vez que, para ser homem humanizado e conviver em sociedade em processo civilizatório evolutivo, se faz necessário o ensino da Educação em Direitos Humanos. "A ideia de dignidade deve, pois, garantir a liberdade e autonomia do sujeito" (p. $25)^{1}$ que vive e convive com outros sujeitos.

Portanto, ao se pensar em formação humana compreendo essenciais os estudos no campo da complexidade, baseado nas ideias de Morin ${ }^{2,3}$, que considera a formação do sujeito complexa a partir das relaçóes humanas, presentes em suas histórias de vida. Enquanto um sujeito constituído de marcas de identidades com singularidade e multiplicidades específicas, a sua formação se forja ao sabor das relações humanas e das diferentes interveniências que este vivencia ${ }^{2-5}$.

A tessitura da formação humana segundo Morin $^{2,3}$ se dá de maneira indissolúvel e complementar, se intercruzando a cada momento da vida. Optando por utilizar esse princípio teórico, posso apontar alguns elementos essenciais na formação universitária na perspectiva da formação humana e cidadã: a singularidade, a multiplicidade, o respeito a diversidade, a compreensão sobre as interveniências sociais e a consciência crítica.

O primeiro deles é questão da singularidade a qual cada ser humano é um ser único singular, indivisível e traz na sua história de vida todas as marcas das diferentes interveniências, as quais se tornam evidências que vão constituindo a sua tessitura complexa enquanto sujeito. Nela está presente a questão da diversidade e consequentemente da multiplicidade em que esse sujeito vive, por ser um sujeito social.

Como cada sociedade tem suas culturas, língua, valores, regras, comportamentos e normas, vale afirmar que o sujeito, mesmo sendo singular, precisa aprender a conviver com a multiplicidade e a multiculturalidade. Destarte, aponto ser importante entáo, estudos sobre a multiculturalidade ${ }^{6}$ crítica, para que o sujeito possa compreender não só a questão relacionada à sua sociedade, mas a sua própria condição de vida na sociedade e com a sociedade. Sendo assim, durante o meu fazer educacional no ensino superior, faço uma relação entre Direitos Humanos e a teoria da complexidade para que os graduandos possam compreender a relaçáo entre a educação em Direitos Humanos e sua própria condiçấo de sujeito de direitos.

Questóes norteadoras são essenciais para esse trabalho, colocando os graduandos para refletirem sobre: o que são direitos humanos? Quais são os fundamentos dos direitos humanos? Quem são os sujeitos de direitos? E por que se faz necessária a compreensão sobre os direitos humanos? Partindo do princípio que os direitos humanos se focam na tese da dignidade e o reconhecimento da pessoa como sujeito de direito, essencialmente já temos a correlação entre o direito e o dever. Sigamos para compreender como se dá essa correlação.

Pelo simples fato de nascermos na espécie humana e vivermos em sociedade, nascemos como sujeitos de direito, o que pressupóe a obrigatoriedade de dever. Sendo assim, para garantia da dignidade do sujeito há o dever de alguém ou de uma instituição que lhe garanta o direito adquirido como sujeito de direito ${ }^{7,8}$. Então, todo direito está relacionado a um dever; não necessariamente o direito que eu tenho está associado ao dever sobre aquele mesmo direito. Por outras palavras, podemos explicar como: se eu tenho direito à vida, esse direito pressupóe que há o dever de outrem a respeitar o meu direito de 
ter a vida. Então, existe uma certa obrigatoriedade fundamental no direito humano do outrem de não colocar em risco a minha própria vida ou a garantia de minha condiçáo de viver ${ }^{1,7,8}$.

Percebam que a relação entre o direito e o dever está associada ao outro. Não obstante, quando eu reconheço os direitos humanos como sendo a essência para todos (os homens e mulheres), a partir do momento que o outro também tem direito à vida, consequentemente o dever de garantir a vida do outro está sobre o meu dever de aceitar as diferenças, respeitar a diversidade e compreender a complexidade humana. Essa relação entre o direito e o dever sempre estará no processo da educação em direitos humanos ${ }^{1,7,8}$.

Como o homem não nasce ontologicamente formado, mas se constitui ao longo de sua história de vida, o processo educativo que possibilite o sujeito a compreender-se humanizado fortalece o processo civilizatório. Para isso exige-se por meio da educação, em diferentes níveis educacionais, que as instituições de ensino assumam o papel social desta formação humana. Esses valores, princípios e fundamentos se fazem necessários também na formação universitária.

\section{O desenvolvimento de educação em direitos humanos nos cursos do CCA/ UFPB}

Como já antecipado, o CCA tem sete cursos distintos com propositura de formação sólida em fundamentos teórico-práticos que possibilitam os estudantes às vivências por meio de diferentes disciplinas e a utilização dos conhecimentos acadêmicos em contextos sociais. Entre tantas disciplinas opto por falar sobre a disciplina de Comunicação e Extensão Rural, que outro professor colega desenvolve nos cursos de Agronomia, Zootecnia e Medicina Veterinária. Essa opção se dá pelo fato de o professor proporcionar aos estudantes a possibilidade de compreender sobre a realidade do trabalho rural e de assentamentos, por meio de visitas in lócus, nas zonas rurais para conhecerem a população, ouvindo suas demandas, compreendendo e analisando a realidade; na qual, possivelmente, esses estudantes poderão trabalhar como estagiários ou futuros profissionais. Compreender a realidade desses sujeitos partindo da escuta sensível, do olhar para a realidade, buscando compreender o outro e seu cotidiano é importante para a construção de novos saberes, o fortalecimento e valorização do conhecimento ${ }^{5,9}$.

A interveniência técnica se dá nesse caso, com respeito e aceitação mútua de conhecimentos distintos (dos técnicos-acadêmicos e da comunidade) para a construção coletiva e mudança na realidade. Nesse caso, específico, vemos a possibilidade da comunidade ter acesso às informações técnicas, alternativas de melhoria na produção, no trabalho e até mesmo nas condiçóes de vida. Quando o professor oportuniza os estudos sobre a realidade e retorna à comunidade com alternativas participativas, os envolvidos (estudantes e comunidade) podem desenvolver empoderamento/autonomia.

Outra disciplina que se apresenta com princípios em educação em Direitos Humanos - e é comum a todos os cursos - é a Educação para as relações Étnico-raciais. Nessa disciplina focam-se os estudos sobre o reconhecimento da identidade e das contribuiçóes dos povos negros e indígenas, na história do Brasil; de maneira a desvelar uma série de fatos históricos e também trazermos a perspectiva de um currículo decolonial. Isso significa que traz em termos de conhecimento, uma análise crítica sobre a construção da identidade brasileira, sobre a cultura e as contribuições de diferentes grupos étnicos. Esse processo torna-se importante e complementar à formação em direitos humanos por desvelar os ensinamentos na educação básica, por meio de um currículo eurocêntrico, que por muitos anos as escolas brasileiras fizeram uso e muitos universitários tiverem acesso ${ }^{10}$.

Como Ferreira e Silva ${ }^{11}$ apontam:

A perspectiva teórica decolonial destaca a premissa fanoniana da cisão do mundo colonizado, ou seja, compreendemos o que o colonialismo, para além da expansão e da conquista territorial, forjou uma nova ordem mundial: o sistema-mundo moderno/colonial, no qual estavam inscritos ideias de justiça, igualdade e liberdade a partir de uma classificaçấo racial da sociedade moderna que atendia aos interesses de alguns poucos donos do mundo. (p. 93)

Nesse sentido, ao se propor fundamentar uma disciplina em bases do ensino decolonizado, permite aos estudantes a compreensão sobre a realidade construída historicamente favorecendo a eles reflexões sobre quem eles próprios são, suas histórias, as diferentes culturas, suas realidades. Quando isso ocorre por meio de debates reflexōes e discussão sobre os problemas brasileiros, à busca de superação do racismo, da discriminação, da valorização da 
diversidade humana e da compreensão sobre o sujeito, proporcionamos à educação em direitos humanos. Principalmente, porque a disciplina de Educação para as relaçóes étnico-raciais visa como foco primário a valorização dos povos brasileiros, e a superação da discriminação racial.

Outras duas disciplinas que estão sob minha responsabilidade, são: a Educação Especial e a Educação e inclusão social. As três disciplinas interligam conhecimentos com as disciplinas de Currículo escolar e Estagio Supervisionado, nas quais os docentes desenvolvem-nas em busca de autonomia e de construção coletiva sobre o fazer docente e prática libertadora ${ }^{4,5}$. Em Educação Especial, na perspectiva inclusiva, o desafio inicial é desconstruir o conceito de capacidade e/ou incapacidade que muitos estudantes das licenciaturas têm sobre às pessoas com deficiência (PcD). Muitos afirmam que é difícil ensinar a uma $\mathrm{PcD}$ ou que não seriam capazes de trabalhar com a diversidade em sala de aula, devido aos preconceitos que trazem da sociedade e na sociedade sobre a PcD. Esse comportamento chamamos de capacitismo.

Etimologicamente, assim como todos os termos terminados com sufixo "ismo", a palavra capacitismo denota uma ideologia que tem uma crença ou uma doutrina. Nesse caso, o termo indica uma discriminação para com a pessoa com deficiência, por identificar que essa náo é capaz de realizar algo, apresentando limitaçóes/déficits. As limitaçóes que possam ser vinculadas a essa população se dá, na maioria das vezes, por falta de oportunidades que a sociedade não lhe oferece para o desenvolvimento de habilidades e competências do sujeito. Sendo assim, o capacitismo para com as pessoas com deficiência está presente na sociedade assim como o racismo está para população negra. Esses comportamentos e atitudes discriminatórios ocorrem em função do não reconhecimento e aceitação das diferenças e das construçôes históricas sociais ${ }^{11,12}$.

$\mathrm{Na}$ Educação Especial são tratados aspectos sobre as diferentes deficiências, assim como sobre as altas habilidades e transtornos de aprendizagem, de maneira a compreender a etimologia de cada necessidade educacional especial e sobre orientações teórico-práticas para a aceitação da diferença e o desenvolvimento das competências e habilidades do sujeito. $\mathrm{O}$ foco náo está na deficiência e sim sobre a possibilidade do futuro professor pesquisar e auxiliar o outro a desenvolver-se e ter garantia de acesso aos diferentes segmentos sociais.

Os graduandos fazem estudos teóricos, debatem o tema, e apresentam proposiçóes práticas para estudos de casos, treinando o olhar pedagógico sobre as diferenças e buscando construir inovações didático-pedagógicas, para o atendimento educacional especial. Sempre tendo como princípio que o ser humano é singular e ao mesmo tempo multidimensional e que se forma na tessitura das relaçôes sociais, além de assumir o papel social que o professor precisa assumir ${ }^{4-5,13}$.

$\mathrm{Na}$ disciplina de Educação e inclusão social, a ideia é proporcionar os estudos sobre as políticas de inclusão social, apresentando sempre a responsabilidade do Estado e trazer a possibilidade dos graduandos estudarem sobre os diferentes grupos vulneráveis em nossa sociedade. Para isso, estudamos teoricamente sobre educação carcerária, políticas para juventude, educação de jovens, educação indígena, partindo de estudos teóricos, vídeos documentários, visitas técnicas e de campo, como por exemplo: visita às instituições de educação especial; comunidades quilombolas, aldeias indígenas, Ongs e outros espaços.

Esse trabalho, às vezes, se desenvolve também com açôes de extensão, em que os graduandos podem conhecer e participar de atividades extensionistas ampliando a possibilidade de conhecer a realidade social e colaborar com a comunidade. Ao sairmos do campus universitário, seja para visitação e conhecimento da realidade, ou seja, para atuar como extensionistas, o foco está em compreender a realidade, identificar as necessidades, respeitar as pessoas como sujeitos de direitos e envolver-se, mesmo que em situaçóes hipotéticas na propositura de açóes na melhoria das condiçóes de vida ou trabalho. O sentimento de pertencimento social é importante para o indivíduo se compreender como membro da sociedade.

Esses princípios não podem ser somente na formação do licenciando. Entendo que todos os profissionais assumem papéis sociais distintos e devem assumir responsabilidades pessoais, entre elas entender que a diversidade é um atributo à humanidade. De acordo com os preceitos legais, todos somos iguais perante a lei, assegurando-se o direito de manter as diferenças e suas opçóes ${ }^{14}$. Como Boaventura Santos ${ }^{15}$ afirma:

Temos o direito de ser iguais quando a nossa diferença nos inferioriza; e temos o direito de ser diferentes quando a nossa igualdade nos descaracteriza. Daí a necessidade de uma igualdade de igualdade que reconheça as diferenças que náo produza, alimente 
ou reproduza as desigualdades (p. 56) ${ }^{15}$.

Analogamente, podemos afirmar que a formação em direitos humanos se sustenta na formação de qualquer profissional pela necessidade de reconhecimento da singularidade/ multidiversidade e à dignidade.

Mas, para todos, inclusive para aqueles que estão participando do Seminário em Direitos Humanos, promovido pela Escola de Educaçáo Física e Esporte da USP, especialmente aos bacharéis e licenciandos em Educação Física, lembro que conhecer sobre os direitos humanos é essencial para autoconhecimento e nossa própria formação. Isso nos possibilita a valorização da diversidade, de reconhecer-se enquanto condiçáo de sujeito social e fortalece o processo civilizatório. Por mais que tenhamos saído de situaçóes de barbáries históricas, anos atrás, a humanidade ainda tem muito a evoluir no processo de reconhecimento sobre a diversidade humana e aceitação das diferenças.

\title{
Palavras finais
}

Quando estudos sobre direitos humanos são oportunizados há a possibilidade de o sujeito abrir-se para novas possibilidades de fazer junto e construir junto, meio a beleza da diferença.

Uma ideia se faz necessária apontar como fechamento e termos em mente: nós vivemos em um arquipélago de certezas sujeitas as mudanças, em meio a um mar de incertezas. Por isso náo existem receitas prontas, prescrições, modelos que devem ser seguidos rigidamente quando se trata de educação em direitos humanos. $\mathrm{O}$ que aqui propus apresentar é uma das inúmeras alternativas do fazer do docente, na busca de proporcionar aos futuros profissionais a compreensão de que nos formamos em parcerias com os demais e convivemos com os demais. Sendo assim, precisamos ser solidários com os outros e construir com os outros.

O mundo muda. O tempo histórico muda. As relaçôes sociais mudam, mas o direito de dignidade humana não pode mudar.

\begin{abstract}
Human rights and vocational training in higher education.

Studies in thefield of human rights havebeen consolidated in recent decades, mainly after the proclamation of the Federal Constitution of 1988, which recognizes the individual as a subject of rights. Considering this, this articleaims to present what are the theoretical-practical assumptions that are present in the training of undergraduatestudents of the courses oftheAgricultural SciencesCenter oftheFederalUniversity ofParaíba in relation to citizen training in human rights and to present how it develops. Thinking about human rights education isnecessaryin professional training, in highereducation, considering thatall professionalsassume technical and social responsibilities when performing their work. Knowing the social reality is differential in professional trainingand canfavordiscussionsand practical proposalstounderstand therealityand modifyit.
\end{abstract}

KEYWORDS: Citizenship; Technical graduation; Human rights. 


\section{Referências}

1. Pequeno M. O fundamento dos direitos humanos. In: Tavares MN et al., organizadores. Direitos Humanos: capacitação de educadores. João Pessoa: UFPB; 2008. p. 24-25

2. Morin E. Os sete saberes necessários à educação do futuro. São Paulo: Cortez; 2001.

3. Morin E. Introdução ao pensamento complexo. Lisboa: Editora Piaget; 1990.

4. Freire P. Pedagogia do Oprimido. Rio de Janeiro: Paz e Terra; 1987.

5. Freire P. Pedagogia da autonomia: saberes necessários à prática educativa. Rio de Janeiro: Paz e Terra; 1997.

6. McLaren P. Multiculturalismos crítico. Cortez: Artmed; 2000.

7. McLaren P. Multiculturalismo revolucionário - pedagogia do dissenso para o novo milênio. Porto Alegre: Artes Médicas Sul. Tradução de Márcia Moraes e Roberto Cataldo Costa. Porto Alegre: Artmed; 2000.

8. Bobbio N. A era dos direitos. Rio de Janeiro: Campus;1992.

9. Roberhorst E. Dignidade humana e moralidade democrática. Brasília: Brasília Jurídica; 2001.

10. Minayo MCS, organizadora. Pesquisa social: teoria, método e criatividade. 26a ed. Rio de Janeiro: Vozes; 2007.

11. Ferreira MG, Silva JF. Currículo e educação das relaçôes étnico-raciais: elementos para construção de práxis curriculares antirracistas. In: Rodrigues ACS, Albino ACA, Süssekind ML, organizadores. Democracia, educação e políticas curriculares nas pesquisas com currículos. João Pessoa: Editora UFPB; 2020. p. 93.

12. Aranha MS. Paradigmas da relação da sociedade com as pessoas com deficiência. Unesp: Impresso; s/d

13. Campos LA. Racismo em três dimensôes: uma abordagem realista-crítica. Rev Bras Ciênc Soc Anpocs. 2017;32(95).

14. Arroyo MG. Ofício de Mestre: imagens e auto-imagens. Rio de Janeiro: Ed. Vozes; 2013.

15. Santos BVS. Reconhecer para libertar: os caminhos do cosmopolitanismo multicultural. Introdução: para ampliar o cânone do reconhecimento, da diferença e da igualdade. Rio de Janeiro: Civilização Brasileira; 2003:56.

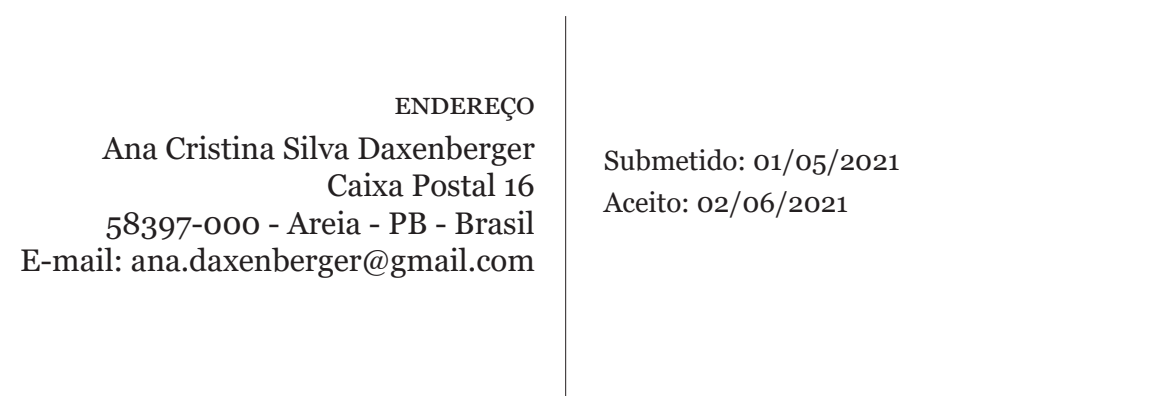

